shift of emphasis from traditional aims towards environmental protection linked with resource conservation and byproduct recovery which, in turn, will offset operating costs.

Although slender by comparison, Dudley's book merits attention as raised nitrate levels are one way in which European Community standards for drinking water have been increasingly breached in Britain. Moreover, the significance of nitrates in food and water is an issue on which researchers disagree, vested interest looms large and public suspicions run high. Dudley carefully presents information on nitrate entry into diets and the putative link between nitrate, nitrosamines and cancer, and punchy sections on "kicking the nitrate habit" consider the costs, politics and methods for reducing nitrates in drinking water, food and the environment. (Curiously, options for nitrate removal receive scant treatment by Gray.)

The chemistry given by Dudley, however, would have benefited significantly from rigorous scientific editing; he has a general and confusing tendency to refer to any form of nitrogen as nitrate. This reservation apart, the extensive up-todate source material will make this a useful popular science book, addressed to the concerned layman rather than the informed specialist.

Roland Bailey, Tony Bark and Roger Miles are in the Division of Biosphere Sciences, King's College, Campden Hill Road, London W8 7AH, UK.

Scotland and John Brinkley in Ireland.

Finally, the author sums up his conclusions. A crisis did occur, but it set in later than is usually imagined. Lack of contact with continental mathematics was more to blame than adherence to any particular symbolism. Throughout the decline, many mathematicians were aware of the problem and fought to put it right. Eventually, this school of thought triumphed; then to some extent it rewrote history and the myth of the dot-age was born.

The author perhaps places a little too much value on the achievements of eighteenth century British mathematicians in developing calculus. Some good work was done, contrary to the myth; but it pales into insignificance compared with the contributions of Euler, Lagrange, Laplace, the Bernoullis and the hordes of continental mathematicians who made the subject the core of mathematical physics. The dot-age may be a myth, but the myth contains more than a grain of truth.

The book, which is documented in great detail, will be of value to anyone interested in this particular period of British mathematics. It also provides a muchneeded reminder that mathematical ideas are transmitted through teaching and cultural influences as well as through research.

Ian Stewart is in the Department of Mathematics, University of Warwick, Coventry CV4 7AL, UK.

- Also recently published by Cambridge University Press, The Preliminary Manuscripts for Isaac Newton's 1687 Principia, 1684-1686 comprises photo-facsimiles of Isaac Newton's manuscripts originally published in 1687 . The manuscripts are selected from the unmatchable collection of Newton's writings in Cambridge University Library. Newton's Principia are considered to be the most influential work that has appeared in the field of mathematical physics and astronomy. In this volume, the manuscripts are annotated by D. T. Whiteside. Price is $£ 60, \$ 110$.

\section{Causes and consequences}

\section{Simon Wain-Hobson}

Retrovirus Biology and Human Disease. Edited by Robert C. Gallo and Flossie Wong-Staal. Dekker: 1990. Pp.409. $\$ 99.75$.

HERE is yet further confirmation that human retrovirology is a most complex and fascinating field. I used to think, having worked on hepatitis B virus, that HBV had everything. Yet the human immunodeficiency viruses (HIV) are just that much more subtle. (I shouldn't quibble as both are, after all, retroviruses of sorts.) In the 400-odd pages of Retrovirus Biology and Human Disease, we are swept through animal and human retroviruses, molecular biology, epidemiology, pharmacology and, of course, clinical AIDS. The editors aim to provide a picture as complete and as broad as possible of the mediagenic yet frightful disease AIDS.

The plan of the book is not surprising, given that Robert Gallo is an editor. The book starts with a historical overview and continues with a walk through bovine and feline leukaemias and their retroviruses, in particular the feline virus, which causes more immunosuppression than leukaemia. These viruses were among the first retroviruses found to be involved in real (out of the laboratory) disease. They pointed the way, even though it was long, to the human T-cell leukaemia viruses (HTLVs). In some ways, the casualty of the search for oncogenic human retroviruses were the ungulate lentiviruses which caused catastrophic sheep loss in Iceland during the 1930s and 1940s. As it happened, the AIDS (or immunodeficiency) viruses turned out to be the first human/primate lentiviruses discovered. It is therefore appropriate, and comforting, to see the ungulate lentiviruses included in a book on human retroviruses.

Adult T-cell leukaemia/lymphoma, its epidemiology and its virus are dealt with next, followed by HTLV-II. This last is an odd fellow in that there are so few cases of HTLV-II. But, sadly, a recent apparition among intravenous drug users means that we are going to see more of this virus.

HIV is extensively covered, from the fine minutae of the $v p u$ gene to problems of treatment by the drug AZT and of vaccines. The chapters on this virus are rather mixed, ranging from vistas to laboratory results. HIV-2 is treated as a HIV-like virus, which will serve only to confuse. The simian viruses get short shrift, which seems unfair as they represent the only way to test hypotheses as to precisely which genetic locus or loci are 